\title{
New Associate Editors
}

We are pleased to announce that the following people have been named as Associate Editors of Acta Anatomica: Brian Hall, Halifax, Antone Jacobson, Austin, Tex., and Don Newgreen, Melbourne, for Developmental Biology; Michael Frotscher, Freiburg i.Br., and Wolfgang Kummer, Giessen, for Neurosciences; Susan Herring, Seattle, Wash., for Comparative and Functional Anatomy; and Finn Boj-sen-Moeller, Copenhagen, and Reinhard Putz, Munich, for Human Gross Anatomy and Biomechanics. It is our hope that their appointments will allow for more direct interactions between authors and editors, to speed up the process of publication further, and to emphasize our desire to publish papers in their indicated areas of expertise. Manuscripts should continue to be submitted to the Editorial Offices in Atlanta or in Basel, from where copies will be forwarded to the appropriate Associate Editors, if applicable, and from where most of the correspondence with contributors will be originated.

We hope you will join us in congratulating these new Associate Editors. Please feel free to consult them about manuscripts you might be preparing.

H.-W. Denkei; Essen AW. English, Atlanta, Ga.

\section{KARGEK}

E-Mail kargerfa’karger.ch Fax+ 41613061234 http://www.karger.ch

(C) 1996 S.Karger AG, Basel 